\title{
Making human beings human: A tribute to Bronfenbrenner's centennial
}

\author{
Sílvia H. Koller ${ }^{\mathrm{a}, \mathrm{b}}$ \\ ${ }^{a}$ Department of Psychology, Universidade Federal do Rio Grande do Sul, Brazil \\ ${ }^{b}$ Optentia Research Focus Area, North-West University, Vanderbijlpark, South Africa
}

Corresponding author. E-mail: silviahkoller@gmail.com

I was given the honor of making a tribute to Bronfenbrenner during the VI International Conference "Early Childhood Care and Education" (ECCE 2017) held on May 10-13th, 2017, in Moscow, Russia. I opened countless files on my computer, started texts, and wrote a paragraph or two, but no more. It was a very challenging invitation for many reasons. First, Bronfenbrenner is one of the most well-known psychologists of our time. Bronfenbrenner was a pioneer of translational and positive Psychology and inspired many environmental intervention programs around the world related to family support services, home visits, and education for parenthood, especially for low-income families and communities. Second, he is a very important figure in my professional and personal life, as a mentor and a wonderful and kind friend. In the beginning, my pages to accomplish this challenging task stayed blank, but not my heart and mind. I had so many ideas and feelings taking root in me that I could hardly decide which were the most relevant. I used to tell my students that when they could not write the first line, they should write the second one. Easier said than done. I looked out at the universe, looking for inspiration. I imagined so many beautiful and true words, but actually, when they appeared on the screen, they did not seem to do justice to the honorable task I had been assigned. Sometimes it seemed sentimental, sometimes distant. It should be so easy to write about Bronfenbrenner, so why could not I? After all, it would be reverencing the one who best defined human development among the theorists of our time. Development is more than change, it is constancy, he used to state. This has a tremendous intrinsic value. In addition, I, who am not given to praying but to expressing gratitude, caught myself repeatedly constrained in search of a light. In addition, this fact was itself constancy!

Bronfenbrenner was not in those theoretical, biographical, empty, and distant paragraphs I had been writing. I knew they would be authentic only if they expressed him. I knew that he was here, within me. It is in human companionship 
where he remains, which turned me more human. His ideas still vibrate intensely in memories and texts. It feels like he is near whenever I start to tell the stories of our brief and intense companionship. When I tell these stories, I see, in the vibrant eyes of my students, the same inquietude that I felt when I was a student of Psychology. When I talked with him and read his texts, my ardent doubts, questions, and retorts made more sense. What I admired most in his works was the lack of certainties, the capacity of self-criticism, and the eternal possibilities that could present themselves. After all, to be human is not to be trivial. There must always be the potential to discover something new about him.

I also reread what I had already written about him in other works and was not satisfied. Other texts about him brought back wonderful memories about his life and our companionship (Koller, 2004) and the profound pain from his loss (Koller, 2005). These texts were mentioned countless times by students and co-workers, who told me how much they came to admire him through my writing. He certainly would have liked to read them. With these recollections and remarks, I started to ask myself what I could do differently now. More than writing about his theories, ideas, or biography, I wanted, again, to write about who he had been to me. More than that, I wanted to write about how human he had been and how similar we all are in our immense diversity. To write about this would also certainly be to learn about and contribute to teaching his theory. I also wanted to write about the Ecological Engagement Methodology that we created in Brazil to apply his theory, and luckily, we had time enough to discuss with him and hear his compliments on our methodological ideas (Koller, Morais, \& Paludo, 2016).

The opportunity of being in Moscow, where he was born, is very significant to me. Certainly, Russian psychologists and students are aware of his importance to the Psychology field, and they should be very proud of his work and legacy to the world and to the studies of child development. Many Psychology students also would like (and perhaps need) to know how similar they are to Bronfenbrenner. His accounts about needing to seek, during youth, works in Psychology to better understand himself seemed so unoriginal and contemporary. But, similar to so many Psychology students, Bronfenbrenner also thought that some subjects taught in university were tedious and absurd (Bronfenbrenner, 1995).

Even having learned, throughout his school years, that Psychology was a science similar to any other that measured, observed, and performed experiments, he was sometimes suspicious of this. He wanted more. He was studying human beings and could not accept the reduction of such a complex psychological reality. Scholarly books showed that there was not just one Psychology but dozens and that the chapters separating psychological fields fragmented something or someone that seemed to him so whole and natural that it, therefore, could not be simple. Facing such a fragmented vision of human beings, Bronfenbrenner continued asking where could be found this man or woman, child or adolescent that they were trying to understand.

With the advance of his studies and an increased worry about these questions, Bronfenbrenner became increasingly convinced that a new way of conceiving and analyzing human development was needed. In his studies about individual differences, he noticed that the Psychology of human beings integrated itself in sequential chapters with environmental influences and genetic factors through- 
out development. However, once again doubts overtook him, which seems to me, brought him closer, in one more way, to so many students discovering the different psychologies during their years in university. Bronfenbrenner, in part, was fascinated by new knowledge but feared that some of the ideas were not properly and experimentally tested. Maybe they had been thoroughly tested but were distant from the ecology of human beings. The use of measuring in the field originated from the idea that Psychology was, after all, a real science, but some measurements seemed alien to him. However, his persistence and knowledge, accumulated as far back as when he lived with his scientist father, showed him that it should be possible to unite such ideas. Maybe more than this, Bronfenbrenner accepted the challenge of creating a Psychology that was definitely a science, with an innovative attitude that is so expected contemporarily. Psychological reality does not occur just in controlled experiments. Bronfenbrenner emphasized the natural experiments that human nature itself experienced during development, saying that these should receive priority. The naturalistic observation of real human beings, in their real environments, interacting with other human beings, objects, and symbols that were also real, even if only to themselves, became the central nucleus to his theory. Science, after all, as Bronfenbrenner emphasized, was "not to verify hypotheses, but to discover new ones, by proving yourself wrong” (1995, p. 606). More than this, he realized that the integration and advance of the science of Psychology only occurs because "psychologists not only did experiments, they also thought - rigorously and systematically — both before and after each experiment" (1995, p. 606). How many Psychology students throughout their school years vigorously shout in favor of this? How many are actually heard by their mentors? How many are silenced? And how silenced they are!

Making human beings more human seems to be a challenging proposal with a touch of pretension and utopia. Who knows? Only a few scholars in Psychology could give such boldness. Only a few scholars would also have the sensibility and commitment to perceive that many human beings live in conditions that do not correspond to their status as a human or that, at the very least, subjugate the humanity (in the greatest sense possible) they should be experiencing. Bronfenbrenner is certainly one of them and, because of this, deserves our greatest respect and admiration.

Bronfenbrenner lived a life of diversities, challenges, and adversities. He was born in 1917 during the Russian Revolution and immigrated with his parents to the United States after an uncle died from hunger. He lived there as the son of a neuropathologist and a Russian mother, who did not allow him to forget and value his Russian language and heritage. In search of a better position, his family survived marginality and poverty, as foreigners did at the time. He received a scholarship at Cornell University, after his father's illness, and graduated with a degree in Music and Psychology. After studying at Harvard University and the University of Michigan, he debuted as a doctor during the Second World War. He then returned to Cornell as a professor and stayed there until the end of his life. He had a long-lasting marriage with a woman of German descent, six children, thirteen grandchildren, and one great-granddaughter by the time of his death in 2005, in Ithaca, New York. His life was marked by concurrent risk and protective factors that showed, in his own experience, just how much being human costs and is worth. 
For Bronfenbrenner, the worlds of human beings were not just the ones he himself had lived in. His legacy is immortal and is an example of how even living through so many battles, someone can be happy and look around with hope and confidence in better worlds. His bioecological theory of human development expresses this. Bronfenbrenner had the conviction that the world was immense and filled with opportunities and that human beings could be in it to improve their own lives and those with them in that journey. Of the experience he achieved through Psychology and the knowledge he passed on, perhaps these have been the most fertile. Studying human beings, making a science about them, let us believe there are always possibilities. One theory - his theory - should be able to find a reason for being and be applied to improve the quality of life of all human beings. Why would it be, then, pretentious to propose turning human beings into beings even more human?

Bronfenbrenner was a boy immigrant running from war into a strange country. He accompanied his father in daily journeys to an institution for the "mentally deficient" in which was his house. No barbed wire passed from his house's door and surrounded the entire institution. In this setting, he heard every day about how to perform science and how the truths it could present should be doubted. He learned in every detail how to see widely. Starting his studies in a school for boys of different ethnicities and ages, where he learned English and much about North American culture, made him transit ecologically through many roles and contexts. It was up to him, in his family, to come back home to "Americanize" his parents.

Bronfenbrenner performed an active role in the conception of intervention programs in human development, such as Head Start. His ideas and ability to transform ideas into possibilities for understanding and perfecting natural environments for human development inspired efficient and successful social policies to detain the poverty cycle and exclusion of many human beings. Comprehensive education, health, nutrition, and the involvement of families in several participation and discussion contexts showed his visionary attitude of a truly healthy ecology for human development.

I was privileged to know Bronfenbrenner during his life. Therefore, I could share with him my book about his work, published in Portuguese, in Brazil (Koller, 2004) and discuss the ideas and all the intriguing questions (as he used to say) of my research team about his theory. In 2003, during my last visit with him in Ithaca, I had a chance to discuss the ecological engagement methodology proposal. He was really open to it and even said: "I wish I have enough time to see your methodology being applied and the results you are going to get through the use of it!" In 2003, Cecconello and I published a paper about the ecological engagement as a scientific method based on the Bronfenbrenner's ecological theory of human development. Our main idea was that through naturalistic data collection with scientific rigor data could be considered ecologically valid. The researchers could be sure that the analysis done by them on naturalistic data is definitely well based in the perception and daily experience of the participants. Eventually, more than enabling the accomplishment of research in a natural environment with ecological validity, the ecological engagement provided researchers social interaction with participants, acting also as an intervention. Later, Eschiletti-Prati et al. (2008) proposed a review of Ecological Engagement in greater detail, revisiting the con- 
cepts of bioecological approach (process, person, context and time) and the contributions previously offered by Cecconello and Koller (2003). However, they went further, bringing examples of research that used the methodology in order to propose its operationalization. Some of these studies can be seen in Koller, Morais, and Paludo's book chapters (2016). Some steps should be taken to consider the use of Ecological Engagement Methodology, as Bronfenbrenner advised: 1) A profound knowledge about the Ecological Theory of Human Development, and a rigorous training about methodology, ethics, and data analysis; 2) The construction of the field diary by each member of the research team in order to analyze the participants' proximal processes, as well as of the members of the research team; 3) the participation of the researchers in several activities with the participants in formal and informal moments of the data collection; 4) a period of developing bonds with participants and institutions; and 5) a combination and integration of several strategies of data collection (interviews, tests, scales, etc.). The use of quantitative and qualitative strategies is strongly recommended. The researchers' act of being close to the context being researched, as well as to the knowledge they have about the particularities of the individuals' life and history, allows a much more complex and pertinent discussion and analysis of the collected data. This approach assures the quality of the collected data. The act of being close to the participants' context, as well as the knowledge of their personal characteristics and of their developmental processes during their lifespan, also allows the possibility of a much richer discussion and analysis of data. It may be said, this way, that the "data gain life" through engagement. In addition, even when the results are shown in numbers, percentiles and the results of statistical tests, one will know the "kind" of person and reality he/ she is working with. The data gain, if one can say that, sense. As previously noted, especially in the systematization proposed by Cecconello and Koller (2003), the methodological proposal of Ecological Engagement implies the direct and indirect use of intervention strategies and the transformation of contexts and realities (objective and subjective) that researchers face. The situations are the most diverse ones, evolving from moments in which guidance is given by the research team to the participants (rights, sexuality, etc.), in addition to the denouncement/report of abuse cases and sexual exploitation, the creation of a favorable atmosphere to the expression of feelings and personal sufferings and/or the use of findings to subsidize several programs of intervention, through the dialogue of studies' data with the professionals of different institutions.

Throughout his life and career, Bronfenbrenner pursued three reinforcing themes. First, he always required a good theory for human development. Second, this theory should be implicated in and applied to social policies and strategies for improving the life quality of human beings in their environments. For him, "there is nothing as practical as a good theory" (Bronfenbrenner, 1978, p.48). Third, that to disseminate knowledge, researchers had to always communicate their findings to various audiences through publications, lectures, and debates. His goal was to teach, disseminate, and transform. University students, research co-workers, social policy makers, families, the public in general, and politicians were his permanent target in his inquietude to pass on what he had learned by being human. Bronfenbrenner emphasized the use of naturalistic methods, of observing the real life of human beings. The most sophisticated argument in defense of the superiority of 
these methods compared to experimental studies on humans denounced the practical and ethical impossibility of manipulating and controlling the most significant variables for psychological development.

The preservation of the good species of dear "uncle Bronfy", as we call him in our Study Center, is guaranteed. Being human, noun or predicate, is a rich expression difficult to define. Bronfenbrenner lived a long life and had the ability to look within and try to understand himself. This was his reason for seeking the study of Psychology. It does not seem very original; actually, it seems trivial and common, as it has been repeated many times to us as students of Psychology. Bronfenbrenner's humanity is what fascinates throughout his history and work, and having finished this writing, perhaps I now only have to look through the window and give thanks.

\section{References}

Bronfenbrenner, U. (1978). Lewinian space and ecological substance. Journal of Social Issues, 33(4), 199-212. doi: 10.1111/j.1540-4560.1977.tb02533.x

Bronfenbrenner, U. (1995). The bioecological model from a life course perspective: Reflections of a participant observer. In P. Moen, G.H. Elder, \& K. Lüscher (Eds.), Examining lives in context: Perspectives on the ecology of human development (Vol. 1, pp. 599-618). Washington, DC: American Psychological Association. doi: 10.1037/10176-017

Cecconello, A.M., \& Koller, S.H. (2003). Ecological engagement in the community: A methodological proposal for studying families under risk situation. Psicologia. Reflexão e Crítica, 16, 515-524. doi: 10.1590/S0102-79722003000300010

Eschiletti-Prati, L., Paula Couto, M.C., Moura, A., Poletto, M., \& Koller, S.H. (2008). Revising the ecological engagement: A proposal to systematization. Psicologia. Reflexão e Crítica, 21, $160-169$.

Koller, S.H. (2004). Ecologia do desenvolvimento humano: Pesquisa e intervenção no Brasil (Ecology of human development: Research and intervention in Brazil). (2nd ed). São Paulo: Casa do Psicólogo.

Koller. S. H. (2005). Urie Bronfenbrenner - Obituário (Obituary). Pensando Famílias, 7(9), 161-163.

Koller, S.H., Morais, N.A., \& Paludo, S.S. (2016). Inserção ecológica: Um método de estudo do desenvolvimento humano (Ecological engagement: A study method in human development). São Paulo: Pearson/CasaPsi. 